\title{
Histopatologia e Imunopatologia de Glândulas Salivares Menores de Pacientes com Síndrome de Sjögren (SSj) $)^{(*)}$
}

\section{Histopathology and Immunopathology in Minor Salivary Glands of Patients with Sjögren's Syndrome (SSj)}

\author{
Karin Spat Albino Barcellos ${ }^{(1)}$, Luís Eduardo Coelho Andrade ${ }^{(2)}$
}

\section{RESUMO}

A síndrome de Sjögren (SSj) é uma doença auto-imune caracterizada por infiltração linfocitária em glândulas exócrinas e destruição do tecido glandular, com franca preferência por glândulas salivares e lacrimais. O infiltrado inflamatório inicia-se ao redor das células epiteliais ductais, espalhando-se e substituindo o tecido funcional. Consiste predominantemente de células T $\mathrm{CD}^{+}$e, em menores quantidades, células $\mathrm{T} \mathrm{CD} 8^{+}$, células $\mathrm{B}$ e plasmócitos. O infiltrado plasmocitário consiste de grandes quantidades de plasmócitos contendo IgG e IgM. Alguns estudos revelaram um padrão predominante de citocinas Th1 e expressão de quimiocinas nas glândulas salivares menores de pacientes com SSj. Foi observado, também, um aumento na expressão de moléculas de adesão endotelial e linfocitária nessas glândulas salivares. Foi documentada a expressão do antígeno HLA-DR pelas células epiteliais glandulares de pacientes com SSj e a presença de estruturas semelhantes a centros germinativos em glândulas salivares menores de alguns pacientes. Os mecanismos que desencadeiam o processo inflamatório em glândulas salivares menores de pacientes com SSj ainda não são conhecidos, mas recentes estudos demonstraram que as células epiteliais glandulares desses pacientes estão implicadas na patogênese da doença.

Palavras-chave: síndrome de Sjögren, glândulas salivares menores, histopatologia.

A síndrome de Sjögren (SSj) é uma doença auto-imune com manifestações primárias nas glândulas salivares e lacrimais, sendo clinicamente caracterizada por secura oral (xerostomia) e ocular (xeroftalmia). É uma doença pro-

\begin{abstract}
Sjögren's syndrome (SSj) is a chronic autoimmune disorder characterized by lymphocytic infiltration of the exocrine glands with concomitant destruction of the glandular tissue, affecting predominantly salivary and lacrimal glands. The inflammatory infiltrate begins around ductal epithelial cells, extending and replacing the functional tissue. It consists predominantly of $C D 4^{+} T$ cells, with fewer $C D 8^{+} T$ cells, $B$ cells, and plasma cells. The plasmacellular infiltrate consists of large amounts of IgG and IgM containing plasma cells. Some studies have revealed a predominant Th1 pattern of cytokines and chemokine expression in minor salivary glands of SSj patients. An increased expression of vascular endothelial and lymphocyte adhesion molecules was found on the minor salivary glands of patients with SSj. It was documented that glandular epithelial cells of SSj patients express HLA-DR antigens, and that structures resembling ectopic germinal centers were found in minor salivary glands of SSj patients. The mechanisms that initiate the inflammatory process in minor salivary glands of SSj patients remain unknown, but recent studies have shown that the glandular epithelial cells of SSj patients have a role in the pathogenesis of the disease.
\end{abstract}

Keywords: Sjögren's syndrome, minor salivary glands, histopathology.

gressiva em que o sistema imunológico reage contra antígenos presentes nessas glândulas, havendo destruição inflamatória das glândulas exócrinas. Em razão da maior acessibilidade, a maior parte dos estudos histológicos refere-se às

\footnotetext{
* Trabalho realizado na Disciplina de Reumatologia da Universidade Federal de São Paulo - Escola Paulista de Medicina (Unifesp-EPM), São Paulo, SP, Brasil. Recebido em 27/01/2005. Aprovado, após revisão, em 31/03/2005.

1. Pós-graduanda na Unifesp-EPM.

2. Professor adjunto - Livre docente na Unifesp-EPM.

Endereço para correspondência: Dra. Karin Spat Albino Barcellos. Rua Botucatu, 740 - 3ªndar, CEP 04023-062. São Paulo, SP, Brasil. Tel. 55 (11) 5576-4239; e-mail: kbarcellos@hotmail.com
} 
glândulas salivares menores. Vários estudos pesquisaram e descreveram os tipos celulares encontrados no infiltrado glandular, as citocinas e quimiocinas presentes nesse processo imunológico, a expressão de moléculas de adesão no infiltrado e no tecido glandular, entre outras características importantes para um melhor entendimento da patogênese da doença e dos mecanismos de destruição inflamatória das glândulas salivares na SSj. Nesta revisão, inicialmente serão descritas a histologia e estrutura das glândulas salivares normais, para uma posterior compreensão das alterações histopatológicas e imunopatológicas encontradas nesses órgãos alvos da doença.

\section{HISTOLOGIA E ESTRUTURA DAS GLÂNDULAS SALIVARES}

As glândulas salivares são um grupo de glândulas exócrinas localizadas na boca e vertem suas secreções para a cavidade oral, formando no conjunto a saliva. Cada glândula salivar é formada por elementos parenquimatosos revestidos e sustentados por tecido conjuntivo. O parênquima é formado por ácinos e um sistema de ductos. $\mathrm{O}$ tecido conjuntivo, por sua parte, forma o estroma glandular, que é composto por uma cápsula e septos conjuntivos que dividem grupos de ácinos e de ductos em lobos e lóbulos. O estroma, além de fornecer o suporte para o parênquima, contém os vasos sanguíneos e linfáticos e os nervos que suprem as glândulas.

\section{PARÊNQUima gLANDULAR: CÉLULAS ACINARES E SISTEMA DE DUCTOS}

O parênquima glandular salivar é formado por ácinos que se abrem em uma série de ductos. O sistema de ductos é formado por ductos intercalares, ductos estriados e ductos excretores. Os ductos intercalares são os menores ductos do sistema e os mais próximos aos ácinos. Os ductos intercalares têm continuidade com ductos maiores, os ductos estriados e esses, por sua vez, reúnem-se em ductos progressivamente de maior calibre, os ductos excretores. Os ácinos podem ser constituídos por células serosas, por células mucosas ou pelos dois tipos de células ao mesmo tempo. As células serosas são identificadas como células piramidais, com núcleo esférico, e as células mucosas, com núcleos achatados localizados em sua base.

GLÂNDULAS SALIVARES MAIORES: PARÓTIDA, SUBMANDIBULAR E SUBLINGUAL

Os três pares de glândulas salivares maiores estão localizados fora da cavidade oral propriamente dita, para onde enviam sua secreção através de grandes ductos excretores. As glândulas salivares maiores são constituídas por grande número de ácinos, ao redor das quais o estroma é muito bem desenvolvido. As glândulas salivares maiores são as parótidas, as submandibulares e as sublinguais.

A parótida é uma glândula cujos ácinos são constituídos por células serosas. O estroma apresenta acúmulos de tecido adiposo no seu interior, o qual aumenta com a idade; além disso, em geral, toda glândula parótida apresenta um ou mais linfonodos no seu estroma, que foram incorporados durante o desenvolvimento. A submandibular é uma glândula mista onde a maioria dos ácinos é constituída por células serosas; o restante dos ácinos é mucoso, a maioria com semilua serosa. As glândulas sublinguais diferem das duas anteriormente descritas por não serem, cada uma delas, uma única glândula envolvida por uma cápsula de tecido conjuntivo; são, na verdade, um conjunto de glândulas muito próximas que estão ligadas por um estroma comum e envolvidas por uma delicada cápsula, localizado na membrana mucosa do assoalho bucal. Nas glândulas sublinguais quase a totalidade dos ácinos apresenta células mucosas com semiluas serosas.

\section{GLÂNDULAS SALIVARES MENORES}

$\mathrm{Na}$ mucosa que recobre todas as regiões da cavidade oral, ou na sua submucosa, com exceção de gengiva e da porção anterior do palato duro, existem numerosas e pequenas glândulas salivares. A maioria delas apresenta suas unidades secretoras terminais entremeadas no tecido conjuntivo das mucosas de revestimento da boca, principalmente na submucosa ou entre as fibras musculares da língua, conforme sua localização. A maioria das glândulas salivares menores é constituída por ácinos com células mucosas e serosas (semiluas), tendo por isso uma função glandular do tipo mista. Das glândulas salivares menores saem curtos ductos que se abrem na cavidade oral. Essas glândulas recebem sua denominação segundo a região onde se apresentam; assim, existem glândulas labiais, bucais, palatinas, glossopalatinas e linguais ${ }^{(1)}$.

\section{HISTOPATOLOGIA DAS GLÂNDULAS SALIVARES EM PACIENTES COM SSJ}

\section{GLÂNDULAS SALIVARES MENORES}

A principal característica patológica da SSj é o infiltrado linfocítico focal que consiste em agregados de linfócitos, começando ao redor dos ductos, espalhando-se, envolvendo o lóbulo inteiro das glândulas salivares. Há uma 
destruição das células epiteliais pelo infiltrado linfocitário, levando a uma substituição do tecido glandular por células mononucleares. Embora alguns lóbulos sejam completamente destruídos, a arquitetura pode estar preservada, com outros lóbulos intactos e aparentemente normais. A associação de hiperplasia do epitélio do ducto salivar e infiltrado linfocítico se traduz clinicamente por aumento da glândula ${ }^{(2)}$. Além do infiltrado linfoplasmocitário, outras características histopatológicas podem ser encontradas nos cortes histológicos de glândulas salivares menores dos pacientes com SSj, como ectasia e proliferação ductal, substituição dos ácinos por fibrose, edema, proliferação vascular e progressiva substituição do parênquima por tecido adiposo. Células como histiócitos, mastócitos e monócitos também podem estar presentes nas glândulas de alguns pacientes, sendo rara a presença de células natural killer $^{(3)}$. A Figura 1 ilustra algumas dessas alterações encontradas em glândulas salivares menores de pacientes com SSj.

Uma avaliação de biópsias de glândulas salivares de pacientes com SSj por microscopia eletrônica demonstrou um contato direto entre as células linfóides e as células epiteliais das glândulas salivares; e, normalmente, não foram observados depósitos de complexos antígeno-anticorpo nas membranas basais circundando tanto os vasos sanguíneos quanto as células epiteliais das glândulas salivares. Esses achados sugerem um mecanismo mediado por células de destruição das células epiteliais das glândulas salivares pelos linfócitos infiltrantes ${ }^{(4,5)}$.

\section{GLÂNDULAS SALIVARES MAIORES}

As lesões linfoepiteliais nas glândulas salivares maiores consistem de proliferação de células ductais e de densos infiltrados linfocitários que substituem o parênquima glandu$\operatorname{lar}^{(6)}$. O infiltrado linfocitário é inicialmente peritubular e se alastra, centrifugamente, conforme os ácinos se atrofiam progressivamente e desaparecem. A proliferação das células dos ductos pode levar à formação das assim chamadas ilhotas epimioepiteliais. Essas ilhotas, que são arredondadas ou lobuladas, consistem de células frouxamente agrupadas, com núcleos vesiculados e membranas celulares mal definidas, por vezes um espaço central semelhante à luz. A aparência final inclui completa destruição dos ácinos e sua substituição por células mononucleares que, embora preencham o lóbulo glandular, não cruzam os septos interlobulares e permanecem dentro da cápsula ${ }^{(7)}$. Células B e T podem ser segregadas em áreas separadas, à semelhança daquelas em tecido linfóide organizado(6). As ilhotas epimioepiteliais estão dispersas, mais ou menos regularmente, por entre os

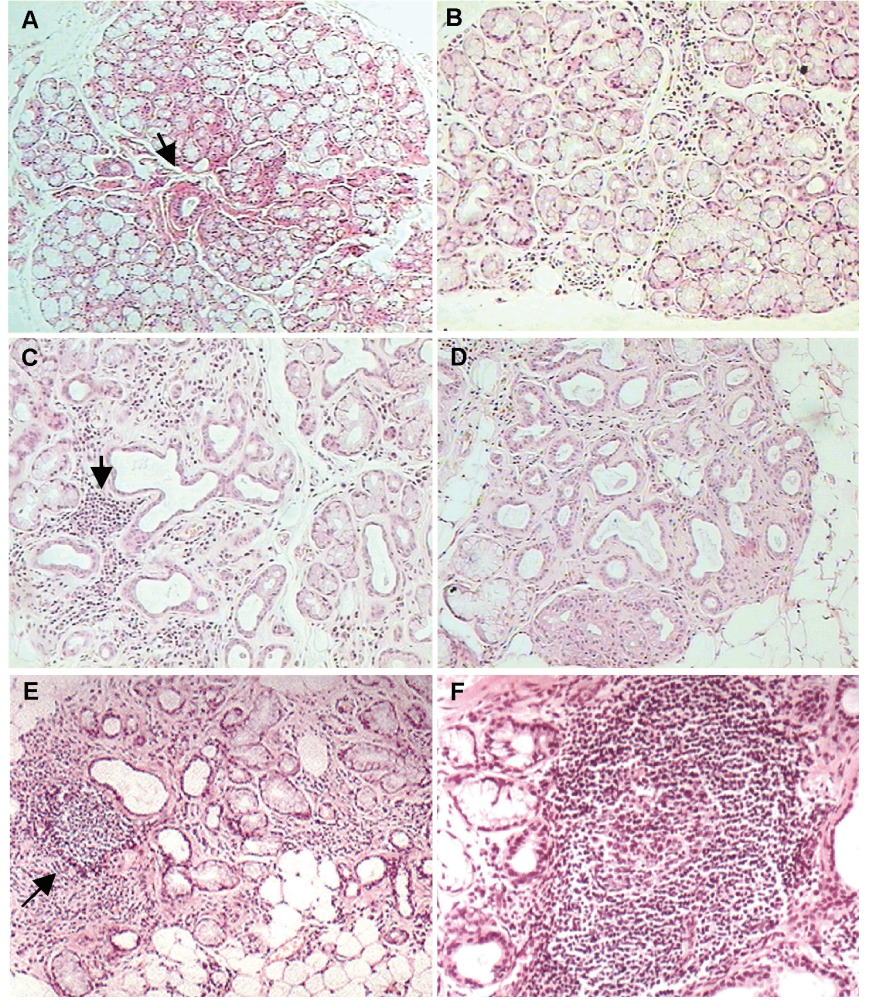

Figura 1 - A) Corte histológico de glândula salivar menor de paciente com SSj mostrando dilatação ductal leve (seta), ácinos de aparência normal e preservação da arquitetura glandular (100x). B) Corte histológico de glândula salivar menor de paciente com SSj onde se observa um infiltrado linfoplasmocitário moderado e ácinos de aparência normal (100x). C) Corte histológico de glândula salivar menor de paciente com SSj mostrando infiltrado linfoplasmocitário formando agregado (seta), dilatação e proliferação ductal, destruição dos ácinos e presença de edema (100x). D) Corte histológico de glândula salivar menor de paciente com SSj onde se observa infiltração gordurosa, dilatação ductal e acentuada proliferação de ductos, com ausência quase completa de ácinos $(100 x)$. E) Corte histológico de glândula salivar menor de paciente com SSj mostrando um foco linfoplasmocitário (seta), infiltração inflamatória difusa do parênquima glandular, dilatação ductal, diminuição de ácinos e infiltração gordurosa (100x). F) Corte histológico de glândula salivar menor de paciente com SSj onde se observa foco linfoplasmocitário com arranjo folicular, com centro germinativo bem desenvolvido formando verdadeiro folículo linfóide (400x)

linfócitos com deposição de material hialino. Essas ilhotas são vistas raras vezes nas glândulas labiais, ou menores; exceto por isso, as modificações nas glândulas labiais espelham aquelas das glândulas principais ${ }^{(7)}$.

\section{CRITÉRIOS DIAGNÓSTICOS PARA SSJ}

A análise histopatológica das glândulas salivares menores submucosas do lábio inferior é uma importante ferramenta 
de diagnóstico da SSj. Um dos mais importantes itens do Critério Europeu para Diagnóstico da SSj é a análise histopatológica dessas glândulas. Esse item é positivo para o diagnóstico da doença quando houver a presença de um ou mais "foco(s)", definido como sendo um infiltrado linfocitário contendo mais de 50 células mononucleares numa área de $4 \mathrm{~mm}^{2}$ (focus score $\left.\geq 1\right)^{(8,9)}$. Há uma graduação para o infiltrado linfoplasmocitário de glândulas salivares menores $^{(10)}$, representada na Tabela 1 . Essa graduação é importante uma vez que os graus 3 (ou 1 foco $/ 4 \mathrm{~mm}^{2}$ de tecido glandular) e 4 (ou mais de 1 foco $/ 4 \mathrm{~mm}^{2}$ de tecido glandular) são alterações sugestivas da SSj.

TABELA 1

GRAU DE INFILTRADO LINFOPLASMOCITÁRIO DE GLÂNDULAS SALIVARES MENORES

\begin{tabular}{ll}
\hline GRAU & Infiltrado linfoplasmocitário/4 $\mathrm{mm}^{2}$ de área glandular \\
\hline 0 & Ausência de alterações histológicas \\
1 & Infiltrado em grau leve \\
2 & Infiltrado em grau moderado \\
3 & Formação de um foco \\
\hline 4 & Formação de mais de um foco \\
\hline
\end{tabular}

\section{INFILTRADO CELULAR EM GLÂNDULAS SALIVARES MENORES DE PACIENTES COM SSJ}

\section{LINFÓCITOS}

A maioria dos linfócitos do infiltrado linfoplasmocitário é representada por células T, mas 10\% a 20\% dos linfócitos infiltrantes são células B. As células B são encontradas na maioria das vezes nas margens dos focos de infiltrados, mas também estão presentes como pequenos conglomerados ao longo de todo o parênquima ${ }^{(11,12)}$. Tem sido demonstrado que um aumento nos pequenos agregados de plasmócitos pode preceder os infiltrados de linfócitos focais ${ }^{(13)}$. Skopouli et al. ${ }^{(14)}$ mostraram que a proporção entre linfócitos $\mathrm{T}$ e B nos infiltrados das glândulas salivares labiais em pacientes com SSj era de 2,5 para 1 . As células B estavam geralmente distribuídas ao redor dos ductos e as células $\mathrm{T}$ ao redor das células B. Foi também demonstrado que as células de memória predominam na lesão, o que talvez explique a intensa ativação de células B observada nos infiltrados focais. A maioria dos linfócitos do infiltrado é representada por células $\mathrm{T} \mathrm{CD}^{+}$, que constituem 60\% a 70\% dos linfócitos infil- trantes, enquanto as células $\mathrm{T} \mathrm{CD}^{+}$representam apenas $10 \%$ a $20 \%$ da população linfocitária ${ }^{(14)}$.

\section{PLASMócitos}

As glândulas salivares menores dos pacientes com SSj são um sítio de produção de auto-anticorpos ${ }^{(15)}$. Os plasmócitos presentes nas glândulas salivares dos indivíduos saudáveis produzem quase que exclusivamente anticorpos do isotipo $\mathrm{IgA}^{(16)}$. Nos pacientes com $\mathrm{SSj}$ o infiltrado plasmocitário consiste de grandes quantidades de plasmócitos contendo IgG e $\operatorname{IgM}^{(11,12,15)}$, com diminuição na porcentagem de células produtoras de IgA e aumento na porcentagem de plasmócitos contendo $\operatorname{IgG}^{(11,17)}$. Matthews et al..$^{(18)}$ observaram que as células IgG e IgM estavam predominantemente localizadas nas áreas de infiltrado linfóide ou adjacentes a elas; enquanto que as células IgA estavam geralmente restritas a áreas normais das glândulas dos pacientes com SSj.

\section{MASTÓCITOS E MACRÓFAGOS (HISTIÓCITOS)}

Mastócitos e macrófagos estão presentes nas glândulas salivares dos pacientes com SSj(19,20). Alguns estudos demonstraram que essas células estão em quantidade aumentada nas glândulas salivares menores altamente comprometidas ${ }^{(19)}$. Konttinen et al. não observaram correlação entre a intensidade do infiltrado linfocitário e o número de mastócitos marcados com azul de toluidina. Entretanto, foi observada uma correlação positiva entre o aumento do escore focal e o número de mastócitos contendo histamina, sugerindo que a proliferação dos mastócitos contendo histamina talvez seja regulada pela inflamação local, possivelmente por meio de mediadores de macrófagos e fibroblastos ${ }^{(20)}$.

\section{CÉLULAS DENDRÍTICAS}

Xanthou et al. ${ }^{(21)}$ estudaram a presença de células dendríticas nas glândulas salivares dos pacientes com SSj. Essas células foram observadas principalmente nas áreas periacinares e periductais próximas aos grandes infiltrados de linfócitos $\mathrm{CD}^{+}$, entretanto não foram observadas nas glândulas salivares dos indivíduos do grupo controle. As biópsias com escore focal $>1,5$ apresentavam folículos linfóides contendo células com morfologia dendrítica. As células dendríticas estavam localizadas entre os linfócitos $\mathrm{T}$ e $\mathrm{B}$ e representavam aproximadamente $2 \%$ das células mononucleares existentes. Em contraste, biópsias de glândulas salivares de pacientes com SSj com um focus score entre 1,0 e 1,5 apresentavam uma população menor de células com morfologia dendrítica e em biópsias com escore focal entre 0,6 e 1,0 estas células não estavam presentes. Observa-se, assim, um provável 
envolvimento das células dendríticas na indução e perpetuação da SSj; bem como sua estreita correlação com a intensidade do processo inflamatório.

\section{PERFIL DE CITOCINAS EM GLÂNDULAS SALIVARES MENORES DE PACIENTES COM SSJ}

Em 1999, Kolkowski et al. ${ }^{(22)}$ estudaram por imunoistoquímica amostras de glândulas salivares de 42 pacientes com SSj primária e observaram que as citocinas relacionadas com a resposta Th1 (IL-2, IFN- $\gamma$, IL-12, IL-18, TNF- $\alpha$ ) estavam abundantemente presentes em quase todas as amostras. A observação de que a maioria dos pacientes expressava IL-2 está de acordo com estudos anteriores de expressão de citocinas em glândulas salivares de pacientes com SSj como os de Dalavanga et al.(3), que demonstraram uma elevada expressão de IFN- $\gamma$ e IL- 2 pelas células infiltrantes das glândulas salivares menores de pacientes com SSj e Ohyama et al. ${ }^{(23)}$, que detectaram a presença dos RNAs mensageiros correspondentes às citocinas IL- 2 e IFN- $\gamma$ em todos os pacientes estudados. Coll et al. ${ }^{(24)}$ demonstraram expressão do receptor de IL-2 por uma grande parte dos linfócitos infiltrantes nas glândulas salivares de pacientes com SSj, reforçando os resultados anteriores. No estudo de Kolkowski et al. ${ }^{(22)}$ não foi observada diferença significativa entre a expressão de citocinas e os graus II, III e IV de comprometimento glandular; entretanto, foi observado um aumento significativo de citocinas efetoras IL-2 e IFN- $\gamma$ nas amostras de pacientes com um tempo maior de evolução da doença.

Boumba et al. ${ }^{(25)}$ encontraram produção abundante de TNF por linfócitos e macrófagos em amostras de glândulas salivares menores de pacientes com SSj. Essa citocina é uma importante mediadora nos fenômenos imunológicos e inflamatórios e sua produção local tem sido implicada em destruição tecidual. Fox et al. ${ }^{(26)}$ demonstraram produção de TNF por células epiteliais das glândulas salivares de pacientes com SSj; a produção desta citocina pró-inflamatória pelas células epiteliais sugere envolvimento dessas células na perpetuação da resposta auto-imune crônica. As células epiteliais não são simples alvos do ataque auto-imune pelas células linfocitárias infiltrantes, mas parecem estar envolvidas na regulação positiva e/ou negativa do infiltrado linfocitário(22).

Kolkowski et al. ${ }^{(22)}$ observaram que as citocinas IL-12 e IL-18 (que induzem o desenvolvimento e a diferenciação das células Th1) estavam igualmente e altamente expressas em todas as amostras, independentemente da evolução da doença, sugerindo a participação dessas duas citocinas na indução e na manutenção da dominância Th1 na SSj. Dessa maneira, as citocinas IL-12 e IL-18 podem ser produzidas por macrófagos e outras células inflamatórias em resposta a uma lesão inicial e ser responsáveis por recrutamento ou diferenciação posterior de linfócitos efetores $\mathrm{CD} 4^{+}$Th1.

Em relação às citocinas envolvidas na resposta Th2, Ohyama et al. ${ }^{(23)}$ detectaram expressão de IL-4 e IL-5 em alguns casos, em associação com forte acúmulo de células B; entretanto, outros estudos observaram ausência de IL-4 nas glândulas salivares menores de pacientes com SSj ${ }^{(22,27)}$. Kolkowski et al. ${ }^{(22)}$ detectaram as citocinas Th2 regulatórias IL-10 e TGF- $\beta$ (produzidas por diversos tipos celulares) na maioria das amostras de glândulas salivares menores de pacientes com SSj; assim como Ohyama et al. ${ }^{(23)}$, que detectaram IL-10, IL-6 e TGF- $\beta$ em todos os pacientes estudados.

Estes achados estão de acordo com os de Fox et al. ${ }^{(26)} \mathrm{e}$ Boumba et al. ${ }^{(25)}$, que demonstraram um padrão predominante de citocinas Th1 em biópsias de glândulas salivares de pacientes com SSj. Ohyama et al. ${ }^{(23)}$ também sugeriram uma função essencial das citocinas Th1 juntamente com as citocinas IL-10, IL-6 e TGF- $\beta$ na indução e/ou manutenção da doença. Como citocinas Th2 também foram detectadas em algumas amostras, foi sugerido o seu envolvimento no progresso do processo da doença, especialmente na ativação de células B locais ${ }^{(22)}$.

\section{QUIMIOCINAS}

As quimiocinas fazem parte de uma família especializada de citocinas que funcionam como potentes mediadores da inflamação pela habilidade de recrutar e ativar subpopulações específicas de leucócitos. Foi observada uma elevada expressão de quimiocinas nas biópsias de glândulas salivares menores de pacientes com SSj ${ }^{(28)}$. Cuello et al. ${ }^{(19)}$ demonstraram que as biópsias dos pacientes com SSj expressavam quimiocinas, enquanto que as dos controles não o faziam. O principal tipo celular expressando quimiocinas nos pacientes era representado por células epiteliais ductais; nas glândulas salivares dos pacientes as células epiteliais ductais e acinares mostraram marcação para todas as quimiocinas examinadas, o que não ocorreu nas glândulas dos indivíduos controles. Este estudo demonstrou que as células epiteliais ductais produzem as quimiocinas MIP- $1 \beta$, MIP- $1 \alpha$, IL-8 e RANTES (Regulated upon Activation, Normal T cell Expressed and Secreted). A IL-8 age preferencialmente em neutrófilos, enquanto que as proteínas inflamatórias de macrófago (MIP-1 $\beta$, MIP-1 $\alpha$ e RANTES) agem prefe- 
rencialmente em monócitos/macrófagos e linfócitos $\mathrm{T}$. MIP-1 $\beta$ foi a quimiocina predominantemente expressa pelas células epiteliais ductais, enquanto que MIP- $1 \alpha$ foi expressa predominantemente por macrófagos. Há evidências in vitro de que MIP-1 $\beta$ age preferencialmente em subtipo $\mathrm{CD}^{+}$ das células $\mathrm{T}$ (as células mais abundantes do infiltrado inflamatório na SSj), sugerindo que essas células sejam seletivamente atraídas para as glândulas salivares menores de pacientes com SSj como um resultado da expressão de MIP-1 $\beta$ pelas células epiteliais ductais.

\section{EXPRESSÃO DE MOLÉCULAS DE ADESÃO E INTEGRINAS EM GLÂNDULAS SALIVARES MENORES DE PACIENTES COM SSJ}

Várias evidências têm indicado que as células epiteliais estão implicadas na patogênese da $\mathrm{SSj}$. A molécula de adesão ICAM-1 (CD54) é uma proteína de superfície expressa em vários tipos celulares, constitutivamente ou após ativação por citocinas. Juntamente com o seu ligante (LFA-1), ICAM-1 participa da adesão leucocitária e na co-estimulação da ativação de linfócitos $\mathrm{T}^{(29)}$. Um aumento na expressão dessa molécula foi observado em glândulas salivares menores de pacientes com SSj ${ }^{(29-31)}$. Em 2001, Kapsogeorgou et al. ${ }^{(29)}$ demonstraram elevada expressão de ICAM-1 por células mononucleares infiltrantes (52\%) e por uma porção significativa de células mioepiteliais periacinares. Ademais, um padrão moderado de expressão de ICAM-1 foi observado em 31\% das células epiteliais ductais nos pacientes com SSj. Esses achados se limitaram aos pacientes com SSj, não sendo observada expressão de ICAM-1 no grupo controle. A expressão dessa molécula de adesão pelas células epiteliais e mioepiteliais foi observada ao longo do tecido glandular, não estando confinada a áreas próximas aos infiltrados linfóides. As células epiteliais e mioepitelias das glândulas salivares menores de pacientes com SSj parecem participar ativamente da indução e manutenção do infiltrado linfocitário no pacientes. Resultados semelhantes foram observados por Azis et al. ${ }^{(31)}$, um aumento na expressão de ICAM-1 pelas células endoteliais, linfócitos, fibroblastos e células epiteliais das glândulas salivares; ademais, foi documentada a expressão de ELAM-1 (Endothelial Leukocyte Adhesion Molecule-1) nas células endoteliais das glândulas salivares dos pacientes e não nas dos controles.
Moléculas LFA-1 parecem apresentar uma importante função na perpetuação da lesão inflamatória nas glândulas salivares. Foi observado que a maioria das células $\mathrm{T}$ infiltrantes nas glândulas salivares menores de pacientes com SSj expressam moléculas LFA-1; a presença dessas moléculas na superfície das células $T$ infiltrantes está correlacionada com um alto número de células de memória ${ }^{(14)}$.

\section{APRESENTAÇÃO DE ANTÍGENOS EM GLÂNDULAS SALIVARES MENORES DE PACIENTES COM SSJ}

Análises fenotípicas das células que participam da patogênese da SSj demonstraram que monócitos e macrófagos apresentadores de antígenos representam menos de $2 \%$ das células existentes $^{(14)}$. Recentes estudos documentaram a participação de células epiteliais das glândulas salivares menores de pacientes com SSj no mecanismo de apresentação de antígeno, já que células acinares e ductais expressam antígenos MHC classe II e moléculas co-estimulatórias B7 $7^{(3,32,33)}$.

A expressão de HLA-DR foi observada freqüentemente nas células endoteliais e nos leucócitos de glândulas salivares menores normais, mas não foi observada em células epiteliais. Por outro lado, nas glândulas salivares de pacientes com SSj, a maioria das células epiteliais expressava o antígeno HLA-DR, principalmente as células epiteliais próximas aos infiltrados linfocitários ${ }^{(3,31,32,34,35)}$. Está descrita a expressão aumentada de moléculas HLADR em células endoteliais, linfócitos, monócitos, células epiteliais ductais e acinares nos pacientes com SSj. Esta expressão diferenciada deve estar envolvida na patogênese da doença, uma vez que tem sido demonstrado que as interações entre moléculas CD4 e HLA-DR medeiam adesão celular ${ }^{(31)}$.

\section{MORTE CELULAR PROGRAMADA OU APOPTOSE EM GLÂNDULAS SALIVARES MENORES DE PACIENTES COM SSJ}

Alguns estudos demonstraram que a destruição das células epiteliais em glândulas salivares menores de pacientes com SSj é mediada por um mecanismo de morte celular programada ou apoptose ${ }^{(36)}$. Duas principais vias foram implicadas neste processo: 1) interações entre células epiteliais expres- 
sando as moléculas Fas e linfócitos $\mathrm{T}$ ao redor expressando Fas ligante (FasL); e 2) secreção de perforina-granzima por linfócitos T citotóxicos (CTL), levando a uma subseqüente degeneração das células epiteliais ${ }^{(37)}$.

Em glândulas salivares normais o antígeno Fas não estava expresso nas células acinares e ductais, entretanto, a expressão do antígeno Fas foi observada nas células epiteliais ductais das glândulas salivares menores de pacientes com $\mathrm{SSj}$, especialmente nos casos de infiltrado celular mais abundante. Esses achados sugerem que o antígeno Fas tenha participação na patogênese da SSj, providenciando um alvo específico para células $\mathrm{T}$ citotóxicas expressando o Fas ligante ${ }^{(38,39)}$.

Kolkowski et al. ${ }^{(22)}$ demonstraram a presença de perforina na maioria das glândulas salivares de pacientes com SSj estudadas; sendo perforina-positivas, pode-se esperar que as células $\mathrm{CD}^{+}$sejam CTLs efetoras. Polihronis et al. ${ }^{(37)}$ demonstraram a presença de perforina e outras moléculas indutoras de apoptose nos infiltrados das glândulas salivares menores de pacientes com SSj, sugerindo novamente que as células $\mathrm{CD} 8^{+}$talvez sejam efetoras funcionais envolvidas na destruição tecidual.

A atividade citotóxica linfocitária é considerada uma propriedade principalmente de células $\mathrm{T} \mathrm{CD}^{+}$e de células natural killer (NK). Entretanto, alguns estudos documentaram a existência de linfócitos T citotóxicos restritos a $\mathrm{CD}^{+}{ }^{+}$classe II. Esta classe de linfócitos T $\mathrm{CD} 4^{+}$com atividade citotóxica utiliza tanto o mecanismo Fas-FasL quanto o da perforina-granzima para desencadear a morte da célula alvo ${ }^{(40)}$. Dessa maneira, Xanthou $G$ et al. ${ }^{(21)}$ examinaram a possível existência de células $\mathrm{T} \mathrm{CD}^{+}$com atividade citotóxica em lesões de pacientes com SSj. Observou-se que $20 \%$ dos linfócitos T CD $4^{+}$expressavam mRNA de perforina nas lesões das glândulas salivares, indicando uma participação dessas células na indução de apoptose nas glândulas salivares menores dos pacientes com SSj.

\section{CENTROS GERMINATIVOS (CGS) EM GLÂNDULAS SALIVARES MENORES DE PACIENTES COM SSJ}

Algumas vezes pode ser observada nas lesões imunopatológicas dos pacientes com $\mathrm{SSj}$ a formação de estruturas linfóides que se assemelham a centros germinativos existentes em folículos primários de órgãos linfóides secundários. Estes CGs em glândulas salivares menores de pacientes com SSj são formados por grandes agregados de células $B$, células $T$ e densas populações de células proliferativas próximas a células dendríticas foliculares. A presença de CG ectópico tem sido documentada em órgãos não linfóides em muitas doenças auto-imunes como no tecido sinovial de pacientes com artrite reumatóide. Alguns estudos sugerem que a formação de microestruturas linfóides em órgão não linfóide tenha uma participação na patogênese de auto-imunidade órgão específica, neste caso na $\mathrm{SSj}^{(21,41,42)}$. A Figura 1-F ilustra um agregado linfóide com centro germinativo em glândula salivar menor de paciente com SSj.

Em conclusão, a síndrome de Sjögren é uma doença inflamatória idiopática, progressiva, acarretando destruição das glândulas exócrinas, predominantemente as salivares e lacrimais. Há infiltração inflamatória dessas glândulas e hiperatividade de células B levando à produção de autoanticorpos locais e circulantes. Um dos principais eventos imunopatológicos observados nas glândulas salivares menores dos pacientes com SSj é a destruição das células epiteliais pelos linfócitos infiltrantes, com subseqüente substituição do tecido glandular por células mononucleares, tecido conjuntivo e tecido adiposo. Os linfócitos $\mathrm{T}$ são as principais células existentes, principalmente células $\mathrm{T} \mathrm{CD} 4^{+}$. Foi observado padrão predominante de citocinas Th1 em biópsias de glândulas salivares de pacientes com SSj e expressão diferencial de moléculas de adesão intercelular em tecido glandular desses pacientes, inclusive pelas células epiteliais. Foi documentada, também, participação das células epiteliais das glândulas salivares menores de pacientes com SSj no mecanismo de apresentação de antígeno e quimiotaxia (Figura 2). Não se sabe por que as glândulas salivares e lacrimais são os órgãos alvos na SSj e qual o fator desencadeante desse processo inflamatório; entretanto, os estudos realizados até o momento têm indicado que as células epiteliais estão implicadas na patogênese da SSj e deixam clara a participação das glândulas salivares no recrutamento celular e no progresso da doença. 


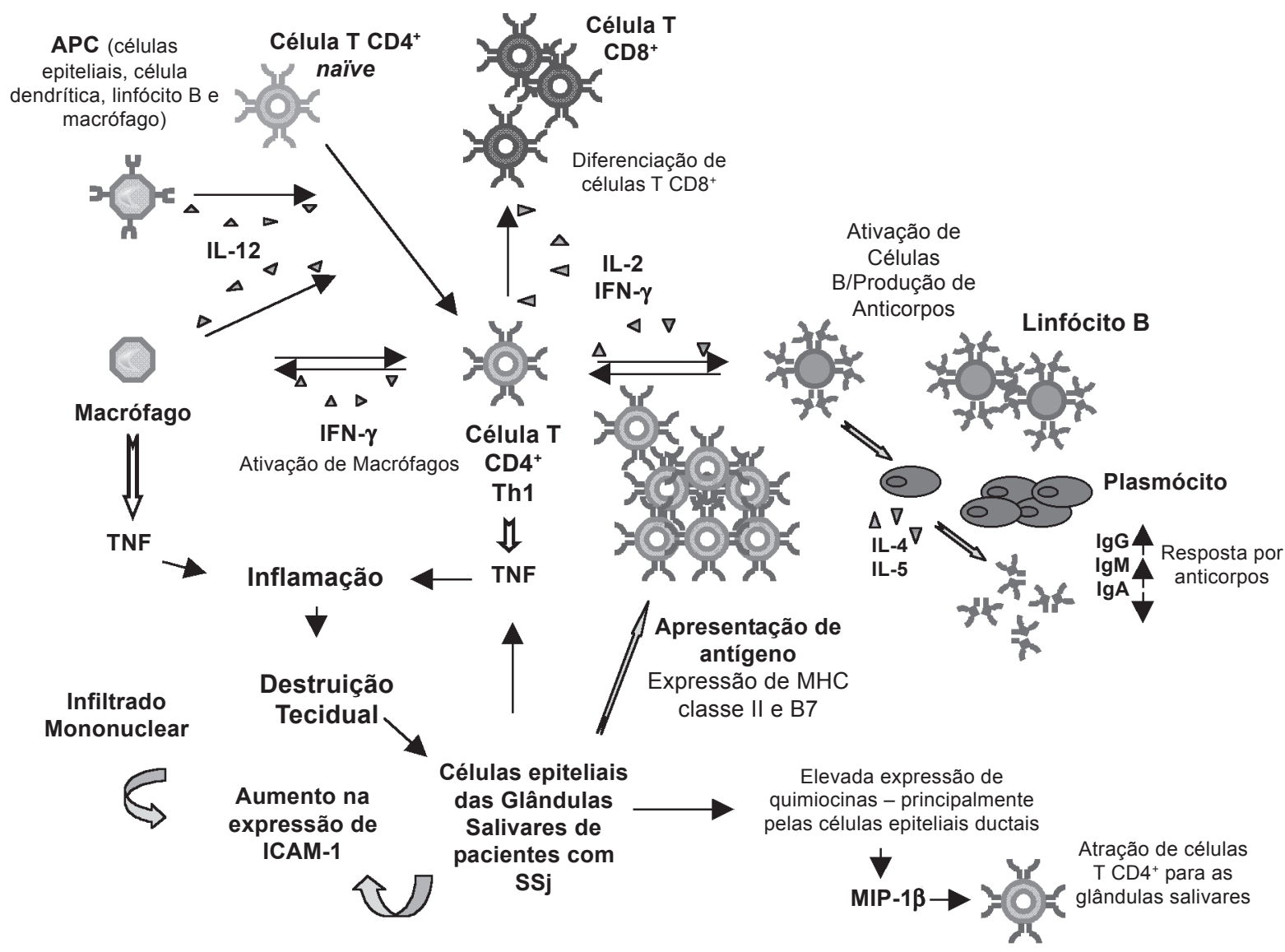

FIgURA 2 - Perfil imunológico de glândulas salivares menores de pacientes com SSj. A maioria dos linfócitos do infiltrado linfoplasmocitário é representado por células T CD4 $4^{+}$, enquanto que as células T CD8 $8^{+}$e os linfócitos B representam cada um 10\% a 20\% da população linfocitária. Nos pacientes com SSj o infiltrado linfoplasmocitário consiste de grandes quantidades de plasmócitos contendo IgG e IgM, com menor porcentagem de células produtoras de IgA. As citocinas relacionadas com a resposta Th1 estão abundantemente presentes nas amostras de glândulas salivares de pacientes com SSj, principalmente IL-2 e INF- $\gamma$, que podem ativar células B e linfócitos T CD8 $8^{+}$, enquanto o INF- $\gamma$ isoladamente pode ativar macrófagos. As células T CD4+, macrófagos e as células epiteliais das glândulas salivares de pacientes com SSj produzem TNF- $\alpha$, uma importante citocina mediadora nos fenômenos inflamatórios. Há uma elevada expressão de quimiocinas nas biópsias de glândulas salivares menores de pacientes com SSj, principalmente pelas células epiteliais ductais. MIP-1ß é a quimiocina predominantemente expressa pelas células epiteliais ductais, agindo em linfócitos T CD4 $4^{+}$. Há um aumento na expressão da molécula ICAM-1 pelas células epiteliais e pelo infiltrado mononuclear nas glândulas salivares de pacientes com SSj. Há a participação de células epiteliais das glândulas salivares menores de pacientes com SSj no mecanismo de apresentação de antígeno, já que células acinares e ductais passam a se comportar como células apresentadoras de antígeno (APC), expressando antígenos MHC classe II e moléculas co-estimulatórias B7

\section{REFERÊNCIAS}

1. Katchburian E, Arana V: Histologia e Embriologia Oral, 1.a ed, São Paulo, Editora Medicina Panamericana, p. 121-49, 1999.

2. Creamer P, Hocherg, MC: Pathogenesis of Sjögren's syndrome. Up To Date 8: 1-7, 2000.

3. Dalavanga YA, Drosos AA, Moutsopoulos HM: Labial Salivary Gland Immunopathology in Sjögren's Syndrome. Scand J Rheumatology Suppl. 61: 67-70, 1986.

4. Fox RI, Howell FV, Bone RC, Michelson P: Primary Sjögren's syndrome: clinical and immunopathologic features. Semin Arthritis Rheum 14: 77-105, 1984.
5. Alpert S, Kang H, Weissman I, Fox RI: Expression of Granzyme A in Salivary Gland Biopsies from Patients with Primary Sjögren's Syndrome. Arthritis Rheum 37: 1046-54, 1994.

6. Speight PM, Jordan R: The molecular pathology of Sjögren's syndrome. In: Isenberg DA, Horsfall A, editors. Autoimmune diseases-focus on Sjögren's syndrome. Oxford, Bios Scientific Publishers p. 25-42, 1994.

7. Cawson RA, Binnie WH, Eveson JW: Atlas Colorido de Enfermidades da Boca, 2a ed, p. 14.8-14.12, 1995.

8. Vitali C, Bombardieri S, Moutsopoulos HM, et al: Preliminary criteria for the classification of Sjögren's syndrome: results of a prospective concerted action supported by the European Community. Arthritis Rheum 36: 340-7, 1993. 
9. Waterhouse JP, Doniach I: Post-mortem prevalence of focal lymphocytic adenitis of the submandibular salivary gland. J Path Bact 91: 53-64, 1966.

10. Chisholm DM, Mason DK: Labial salivary gland biopsy in Sjögren's disease. J Clin Path 21: 656-60, 1968.

11. Lane HC, Callihan TR, Jaffe ES, Fauci AS, Moutsopoulos HM Presence of intracytoplasmic IgG in the lymphocytic infiltrates of the minor salivary glands of patients with primary Sjögren's syndrome. Clin Exp Rheumatol 1: 237-9, 1983

12. Speight PM, Cruchley A, Williams DM: Quantification of plasma cells in labial salivary glands: increased expression of IgM in Sjögren's syndrome. J Oral Pathol Med 199: 126-30, 1990.

13. Cleland-Zamudio S, Demuth M, Trune DR: Pathology of labial salivary gland cellular aggregates in Sjögren's syndrome. Otolaryngol Head Neck Surg 108: 44-50, 1993.

14. Skopouli FN, Fox PC, Galanopoulou V, Atkinson JC, Jaffe ES, Moutsopoulos M: T cell subpopulations in the labial minor salivary gland histopathologic lesion of Sjögren's syndrome. J Rheumatol 18: 210-14, 1991.

15. Anderson LG, Cummings NA, Asofsky R et al: Salivary gland immunoglobulin and rheumatoid factor synthesis in Sjögren's syndrome: natural history and response to treatment. Am J Med 53: 456-63, 1972.

16. Talal N, Asofsky R, Lightbody P: Immunoglobulin synthesis by salivary gland lymphoid cells in Sjögren's syndrome. J Clin Invest 49: 49-54, 1970.

17. De Wilde PCM, Kater L, Baak JPA, Van Huowelingen JC, Hené RJ, Slootweg PJ: A new and highly sensitive immunohistologic diagnostic criterion for Sjögren's syndrome. Arthritis Rheum 32: 1214-20, 1989

18. Matthews JB, Deacon EM, Wilson C, Potts AJC, Hambúrguer J Plasma cell populations in labial salivary glands from patients with and without Sjögren's syndrome. Histopathology 23: 399-407, 1993.

19. Cuello C, Palladinetti $\mathrm{P}$, Tedla $\mathrm{N}$ et al: Chemokine expression and leucocyte infiltration in Sjögren's syndrome. Br J Rheumatol 37: 779-83, 1998.

20. Konttinen YT, Tuominen S, Segerberg-Konttinen M, et al: Mast cells in the labial salivary glands of patients with Sjögren's syndrome: a histochemical, immunohistochemical, and electron microscopical study. Ann Rheum Dis 49: 685-9, 1990.

21. Xanthou G, Tapinos NI, Polihronis M, Nezis IP, Margaritis LH, Moutsopoulos HM: CD4 cytotoxic and dendritic cells in the immunopathologic lesion of Sjögren's syndrome. Clin Exp Immunol 118: 154-63, 1999

22. Kolkowski EC, Reth P, Pelusa F, et al: Th1 predominance and perforin expression in minor salivary glands from patients with primary Sjögren's syndrome. J Autoimmun 13: 155-62, 1999.

23. Ohyama Y, Nakamura S, Matsuzaki G, et al: Cytokine messenger RNA expression in the labial salivary glands of patients with Sjögren's syndrome. Arthritis Rheum 39: 1376-84, 1996.

24. Coll J, Tomás S, Vilella R, Corominas J: Interleukin-2 receptor expression in salivary glands of patients with Sjögren's syndrome. J Rheumatol 22: 1488-91, 1995.

25. Boumba D, Skopouli FN, Moutsopoulos HM: Cytokine mRNA expression in the labial salivary gland tissues from patients with primary Sjögren's syndrome. Br J Rheumatol 34: 326-33, 1995.

26. Fox RI, Kang HI, Ando D, Abrams J, Pisa E: Cytokine mRNA expression in salivary gland biopsies of Sjögren's syndrome. J Immunol 152: 5532-39, 1994
27. Michael DS, Buck RE, Fox PC: Differential cytokine mRNA expression in human labial minor salivary glands in primary Sjögren's syndrome. Autoimmunity 28: 125-37, 1998.

28. Xanthou G, Polihronis M, Tzioufas AG, Paikos S, Sideras P, Moutsopoulos M: Lymphoid chemokine messenger RNA expression by epithelial cells in the chronic inflammatory lesion of the salivary glands of Sjögren's syndrome patients. Arthritis Rheum 44: 408-18, 2001.

29. Kapsogeorgou EK, Dimitriou ID, Abu-Helu RF, Moutsopoulos HM, Manoussakis MN: Activation of epithelial and myoepithelial cells in the salivary glands os patients with Sjögren's syndrome: high expression of intercellular adhesion molecule-1 (ICAM-1) in biopsy specimens and cultered cells. Clin Exp Immunol 124: 126-33, 2001

30. Cauli A, Yanni G, Pitzalis C, Challacombe S, Panayi GS: Cytokine and adhesion molecule expression in the minor salivary glands of patients with Sjögren's syndrome and chronic sialodenitis. Ann Rheum Dis 54: 209-15, 1995.

31. Aziz KE, McCluskey PJ, Montanaro A, Wakefield D: Vascular endothelium and lymphocyte adhesion molecules in minor salivary glands of patients with Sjögren's syndrome. J Clin Lab Immunol 37: 39-49, 1992

32. Moutsopoulos HM, Hooks JJ, Chan CC, Dalavanga YA, Skopouli FN, Detrick B: HLA-DR expression by labial salivary gland tissue in Sjögren's syndrome. Ann Rheum Dis 45: 677-83, 1986.

33. Manoussakis MN, Dimitriou I, Kapsogeorgou E: Expression of B7 costimulatory molecule by salivary gland epithelial cells in patients with primary Sjögren's syndrome. Arthritis Rheum 42: 229-39, 1999.

34. Lindahl G, Hedfors E, Klareskog L, Forsum U: Epithelial HLA-DR expression and T lymphocyte subsets in salivary glands in Sjögren's syndrome. Clin Exp Immunol 61: 475-82, 1985.

35. Franco A, Valesini G, Barnaba V, Silvagni C, Tiberti A, Balsano F: Class II MHC antigen expression on epithelial cells of salivary glands from patients with Sjögren's syndrome. Clin Exp Rheumatol 5: 199-203, 1987.

36. Kong L, Ogawa N, Nakabayashi $\mathrm{T}$, et al: Fas and FasLigand expression in the salivary glands of patients with primary Sjögren's syndrome. Arthritis Rheum 40: 87-97, 1997.

37. Polihronis M, Tapinos NI, Theocharis SE, Economou A, Kittas C, Moutsopoulos HM: Modes of epithelial cell death in Sjögren's syndrome. Clin Exp Immunol 114: 485-90, 1998.

38. Matsumura R, Kagami M, Tomioka H, et al: Expression of ductal Fas antigen in sialoadenitis of Sjögren's syndrome. Clin Exp Rheumatol 14: 309-11, 1996.

39. Matsumura R, Umemiya K, Kagami M, et al: Glandular and extraglandular expression of the Fas-Fas ligand and apoptosis in patients with Sjögren's syndrome. Clin Exp Rheumatol 16: 561-68, 1998.

40. Williams NS, Engelhard VH: Identification of a population of CD4 ${ }^{+}$ CTL that utilizes a perforin- rather than a Fas ligand-dependent cytotoxic mechanism. J Immunol 156: 153-9, 1996.

41. Salomonsson S, Jonsson MV, Skarstein K, et al: Arthritis Rheum 48: 3187-201, 2003.

42. Amft N, Curnow J, Toellner DS, et al: Ectopic expression of the B cell-attracting chemokine BCA-1 (CXCL13) on the endothelial cells and within lymphoid follicles contributes to the establishment of germinal center-like structures in Sjögren's syndrome. Arthritis Rheum 44: 2633-41, 2001. 